\title{
MANIFESTATIONS OF TEACHER PROFESSIONAL AGENCY IN RELATION TO INTEGRATION OF ICT IN TEACHING
}

\author{
Agnese Karaseva \\ University of Tartu, Estonia \\ Vidzeme University of Applied Sciences, Latvia
}

\begin{abstract}
Drawing on the social domain theory of Derek Layder, this qualitative meta-study study aims to propose a novel typology of school teacher professional agency in relation to the process of information and communication technology (ICT) integration in teaching in Latvian and Estonian schools. The typology is built by understanding teachers' choices and practices of technology use as both resourced and constrained by various personal, situational, social and contextual factors. The findings are based on semi-structured interviews with Latvian $(N=16)$ and Estonian $(N=10)$ teachers, class observations, and a study on teachers' information search performance online. Five distinct types of teacher agency manifestation are identified and discussed on three dimensions: pedagogic use of ICT, mediation of students' uses of ICT, and teachers' learning about ICT. Implications for inservice teacher training are discussed.
\end{abstract}

Keywords: ICT integration in teaching; secondary school teachers; social domain theory; teacher professional agency.

\section{Introduction}

Teaching by its nature is a very agentic profession: to be an in-service teacher requires standing for something, taking stances and acting accordingly (Kelchtermans, 2009). Being an in-service teacher means also balancing between different societal pressures and demands posed on teachers due to societal, political and cultural transformations, which we experience recently along changes in production, consumption, social and political relations (Fullan, 2007; Hargreaves, 1994, 2000; Selwyn, 2011). Thus, being a teacher means coping with an ongoing and constant change process (Fullan, 2007). Perhaps the most persistent and long-standing change in teacher work is related to the worldwide attempts to integrate information and communication technology (ICT) in teaching (Selwyn, 2011). It is due to the fact that on policy level for the last decades schools are largely seen as means of preparation of skilled and ICT literate workforce (Apple, 1994; European Commission, 2014; Ward, 2012). Such understanding leads to notion of ICT as an integral part of every school 
subject (Haydn, 2010; Tondeur et al., 2007). Therefore, the teacher responses to pressures related to ICT integration in different school subjects has become an issue of interest in the field of educational technology studies.

This qualitative meta-study aims to propose a novel typology of school teacher professional agency in relation to the process of ICT integration in teaching in Latvian and Estonian schools. Subsequently, the research question, which informs the present study, is the following: How is teacher agency in technology integration process manifested when teachers navigate within various personal, situational, social and contextual influences? To shed the light on these issue, this paper synthesizes the main findings of a list of previous publications where the author of the current paper has contributed during her doctoral studies at the University of Tartu (Karaseva, et al., 2013; Karaseva et al., 2015; Karaseva, 2016a; Karaseva, 2016b; Karaseva et al., forthcoming).

Estonia and Latvia both serve as interesting examples for studying ICT integration in teaching due to several reasons. First, after the collapse of Soviet Union in 1991 digital tools on policy level have been addressed as a powerful means for "catching up" with the West economically, mentally and culturally (Runnel et al., 2009). Such notions have fuelled the process of rapid "internetisation" of Estonian and Latvian schools in second part of 90ties via initiatives such as "Tiger Leap" in Estonia (UNDP, 2003), and "Latvian Education Informatization System" (LIIS) in Latvia (Bicevskis, Andzans, Ikaunieks, Medvedis, Straujums, \& Vezis, 2004). These programs were aiming to equip schools with digital technology, connect them to the Internet and train teachers in ICT skills to be able to integrate digital technology in every subject teaching (Mägi, 2006; Kangro \& Kangro, 2004). Nowadays, both national curricula define digital competences among other core competences (Latvian Ministry of Education and Science, 2013; Estonian Ministry of Education and Research, 2011). Teachers in both countries can autonomously decide about the teaching aids, instructional methods and organization of classroom process, however, as research shows, the policy context for teacher work in both countries is tightening and teachers repeatedly report decrease in their feeling of autonomy (Loogma et al., 2010). It happens due to growing demands related to teacher accountability, responsibility over student attainment in centralized exams, pressures to innovate and keep up with the societal, cultural, and technological changes (Errs, 2015; Loogma et al., 2010; OECD, 2009). Therefore, conceiving teaching profession and integration of ICT in Latvian and Estonian schools as phenomena embedded in specific social, political and economic contexts (Selwyn, 2011), this study draws on the social domain theory of Derek Layder $(1993 ; 1997)$ as its theoretical framework.

The rest of the following paper is structured in the following way: first, the social domain theory of Derek Layder (1997) is introduced briefly; second, the 
concept of teacher professional agency and its manifestations is reviewed. Further, the data collection and data analysis process is described in Methods section, which is followed by Results' part, Discussion and Conclusions.

\section{Theoretical context of the study}

\section{Social domain theory}

Derek Layder $(1993 ; 1997)$ proposed that social life can be understood by looking not only at the often applied dyadic distinction between micro and macro, or individual and the society, but by splitting the social world into four distinct domains. These domains are as follows: 1) the domain of the self (which Layder also calls as the domain of psychobiography), 2) the domain of the situated activity, 3) the domain of the social setting, and 4) the domain of contextual resources.

The domain of psychobiography refers to individual's identity, personal characteristics such as beliefs and perceptions of social world. It contains personal feelings, attitudes, and predispositions that people develop through their lives and also the future aspirations and personal and professional goals which people strive to achieve (Layder, 1997). From the viewpoint of social domain theory, it is important to stress that the domain of psychobiography mediates the perception and interpretations of the other domains, thus it explains why people in similar situations react differently (Layder, 1997).

The domain of situated activity refers to everyday interaction between individuals. Layder (1997) describes it also as the domain of "focused gatherings", - situations that arise when two or more people share each other company for a purpose. Layder (1997) notes that what happens during these "focused gatherings" at face-to-face level depends upon how participants formulate their conduct in the light of their own behaviour and intentions and of the other people who are present.

Speaking about the social organization, according to Layder, the closest to face-to-face encounters and everyday negotiations is the domain of social setting. This refers to proximate, specific location where human interaction takes place. Here the focus shifts from individuals to the workplaces, where the social activities and social practices of people are situated (Layder, 1997).

The fourth domain in Layder's theory is the domain of contextual resources. It can be understood as a set of economic and dominative resources and various forms of hierarchy and inequality on a society-wide basis related to the structure, rules, norms and ownership of economic and cultural resources (Layder, 1997).

Layder (1997) argues that all domains are strongly interconnected and they interact with each other through power, social relations and practices. However, 
a merit of this theoretical framework is that is acknowledges the interconnectedness of the different layers of social life, but denies a stable hierarchy between them, i.e., Layder insists that systemic factors do not determine the psychologies of individuals nor do they determine the nature of interpersonal encounters. And vice versa: psychobiography and interaction between individuals does not cause of determine the functioning of social setting or the contextual environment. Selwyn (2011:50) has noted that "the use of digital technologies within schools is best understood as being situated within all of the social interests, relationships and restrictions that are associated with schools and schooling". Hence, application of social domain theory in the analysis of educational changes related to ICT integration in teaching allows to recognize the subjective and objective factors related to the change process thus helping to understand why there are variations in teachers' responses to educational changes.

\section{Teacher professional agency and responses to educational changes}

Often the notion of human agency is understood in the Giddensian sense as the agent's ability to intervene with the world and make changes to the current situation (Giddens, 1984). Lipponen and Kumpulainen (2011) point towards the idea that agency can also refer to strivings to maintain and reinforce the current state of affairs. Eteläpelto et.al (2013) argue that investigations of professional agency and its' various manifestations require considerations of the relationship between contextual constrains and resources, and professional agency. Understanding the dynamic interplay between these two helps to understand how people create meaning, and cope with professional challenges and take work-related choices (ibid.). The notions of human agency as being resourced both socially and individually (Lipponen \& Kumpulainen, 2011; Vähäsantanen, 2015) have become prominent in the field of educational studies. It is used to address teachers both as professionals doing their work, and as lifelong learners (Eteläpelto et al., 2013), able to make decisions, take stances, and act accordingly thus affecting work-related matters (Ketelaar et al., 2012; Lasky, 2005; Lipponen \& Kumpulainen, 2011).

In the current paper the idea is pursued of teacher professional agency as something that teachers "do" instead of "have" (Fuchs, 2001; Ketelaar et al., 2012; Vähäsantanen et al., 2008). Thus, professional agency can be understood as active management and engagement with contexts of action which is resourced and constrained by various personal, situational, social and contextual factors. Namely, drawing on the framework provided by social domain theory (Layder, 1997), the manifestations of teacher agency can be understood, first, as mediated by various pre-existing teacher beliefs, previous experience, and at the same time also achievement goals and future aspirations (the psychobiographical domain). It can be understood also as emerging from 
interactions and face-to-face encounters with students (the domain of situational activity), third, as influenced by various social and cultural properties of the local context (domain of social setting). Fourth, manifestation of teacher agency can be understood as influenced also by macro level institutional pressures such as educational policies and dominant norms, rules and culture specific aspects (domain of contextual resources).

Teachers are recognized as the key actors in the process of change (Fullan, 2007), and previous research indicates that teacher responses can vary considerably when teachers face different school reforms and policy pressures. Coburn (2004) found five distinct types of teacher responses to educational change: rejection, symbolic response, establishment of parallel structures, assimilation of the proposed policy, and accommodation to the imposed changes. Luttenberg et al. (2013) found four dominant types of responses to educational changes: assimilation, accommodation, toleration and distantiation from the propose reform. Stillmann and Anderson (2015) made a case-study on how a teacher went through the process of appropriation developing an active, agentic, and learning-rich response to policy, stitching together multiple influences, re-authoring and co-authoring the policy, making it "one's own". Vähäsantanen and Billett (2008) described how teachers respond to educational changes through involvement in professional development and active participation, through attempts to balance the existing practices and the pressures to change, through withdrawal from the reform or passive involvement in the form of mere adjustment and toleration of the external demands. Kesküla et al. (2012) analyzed how secondary school teachers in Estonia have responded to curriculum changes since 1990ties including the introduction of the national final examination system. Seven distinctive positions were found in their study, ranging from enthusiastic embracement of the new norms, obedient acceptance and gradual adaption to the new situation to continuation of the previous practice and refusal to change due to a view that curriculum demands are impossible to fulfil. Among other responses, this study detected also refusal to change due to moral objections where the teacher called the national final examinations and excessive curricular demands "unethical with regard to students' interests" (p. 372).

The variety in teachers responses to educational change captured in previous studies should be kept in mind when exploring teacher responses to ICT policies in schools. It is due to the fact teacher professional agency in the context of ICT integration is often conceptualized in two extremes. On one hand, teacher agency is often understood as agency of change (Heijden, Geldens, Beijaard, \& Popeijus, 2015), and teachers being as more or less enthusiastic implementers of externally formulated innovation policies who also serve as policy advocates (agents of change) on peer-to-peer level (Leander \& 
Osborne, 2008). On the other end of the extreme, teacher professional agency is often pictured as resistance towards the new initiatives and change (e.g., see Sannino, 2010; Selwyn, 2011). Such "either - or" view is problematic, because, it leads to instrumentalization of teachers as more or less reliant/ obedient "servants" in the innovation implementation process, refusing to see teachers as professionals who play the key role in implementation of educational innovations (Fullan, 2007). In addition, such "either - or" views poorly cover the richness of realities of practicing teachers who have to find their way within various challenges and opportunities related to ICT integration in teaching, trying to balance their own views and beliefs, and at the same time attend the external pressures and expectations (Selwyn, 2011).

\section{Methods}

\section{Data and participants}

The study presented here is based on re-analysis of findings of five previous studies, which draw on a mix of qualitative and quantitative data deriving from semi-structured interviews with different subject teachers in Latvia and Estonia, a study on teachers' information search performance online, and classroom observations. The empirical evidence was collected in a sample, which consisted of 26 participants: 10 teachers of different subjects from five Estonian- or Russian-speaking schools around Estonia and 16 teachers of different subjects working in a middle-sized school ( $\sim 500$ students) in a regional town in Latvia. In Estonia, teachers came from schools which had participated in activities provided by "Tiger Leap" program (UNDP, 2003). The Latvian sample was formed in the course of a larger action research project aiming to encourage teachers to work with ICT in more creative and diverse ways. All participants, except one, were female. Their work experience at school was rather heterogeneous, ranging from few years to more than 30 years spent in teaching profession. There were 12 science and math teachers, and 14 humanities teachers in the sample. The size of the sample and the method of choosing study participants can be considered as limitations of the study, therefore, there is no ambition to generalize the results or make any crossnational claims. Instead, this exploratory study contributes to the growing body of literature aiming to reclaim "teacher agency in (...) computer-mediated, digital world" (Kimber, Pilley, \& Richards, 2002: 155) and open directions for future research.

\section{Data analysis}

A qualitative meta-analysis approach was applied in order to do a rigorous secondary analysis of the primary empirical findings (Schreibner et al., 1997). The primary studies had utilized a variety of qualitative and quantitative 
approaches to data collection and data analysis. Various theoretical frameworks were employed to examine the influences of different personal, situational, social and contextual factors and relationships between these factors on teachers' practices of ICT integration in teaching. However, conduced in separate studies, they did not provide a comprehensive picture of the phenomenon under investigation - teacher professional agency and its manifestations in relation to the various influences and pressures related to ICT integration policies in education. Therefore the rich empirical foundation established in the individual studies, was employed for the current meta-analysis and development of a novel typology of teacher professional agency manifestations. Figure 1 is a visual summary of how the manifestation of teacher professional agency was conceptualized in the current study, indicating that is resourced and constrained by various personal, situational, social and contextual factors, which were explored in the individual studies.

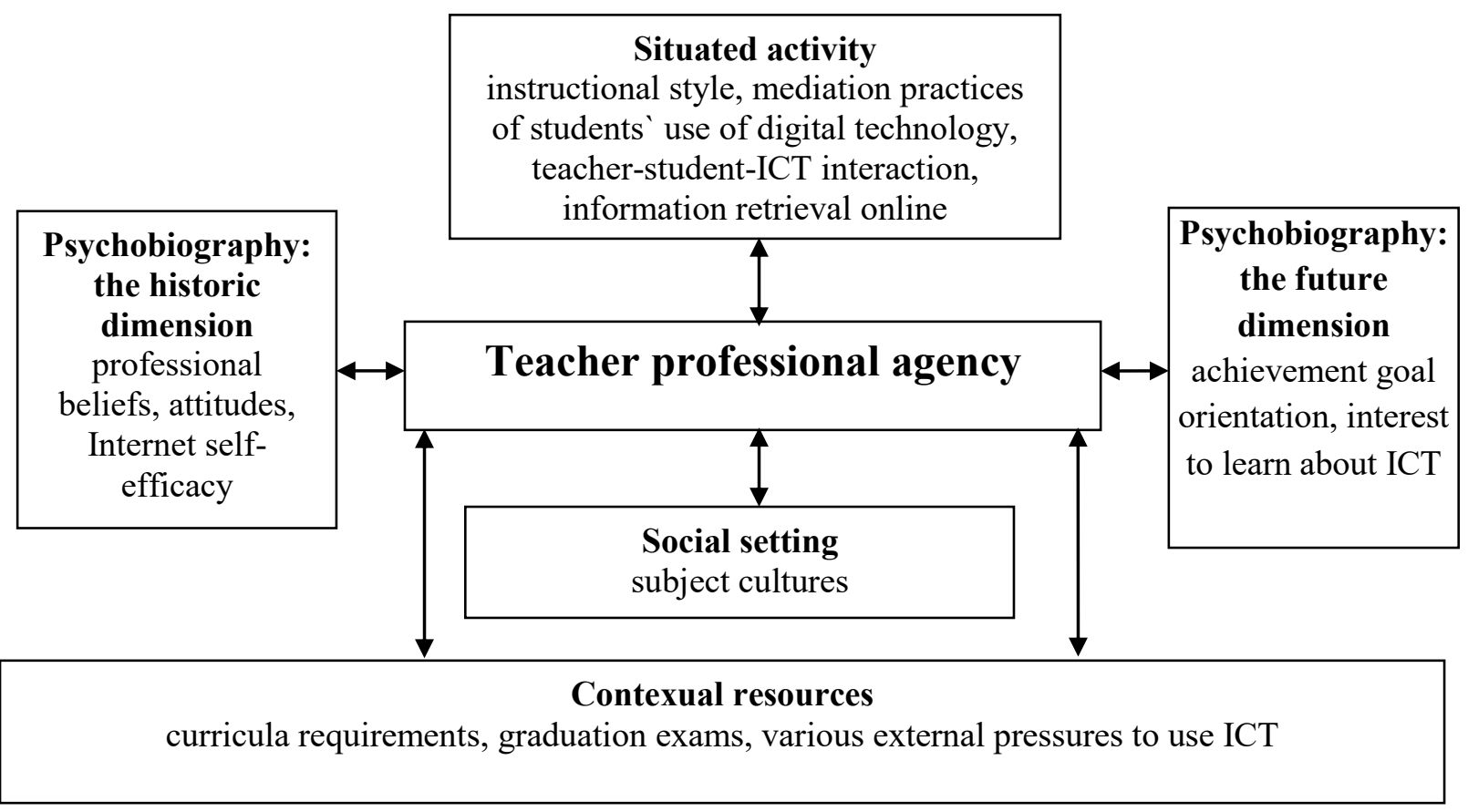

Fig.1 Visual representation of the relationships between teacher agency and various personal, situational, social and contextual influencers

The analysis of the meta-study was interpretative in its nature aiming to employ the findings of the individual studies to develop a typology of manifestations of teacher professional agency paying attention to three important dimensions: teachers as ICT users, teachers as mediators of students' use of ICT, and teachers as learners about ICT. 
In labelling the types of teacher agency manifestations, the term "appropriation" was borrowed from the study of Stillman and Anderson (2015) considering how aptly this term describes the richness of ICT use and the level of co-authoring that teachers demonstrated when making the ICT integration policy "their own". In a similar way, the notion of "ritualism" from the Merton's study (1957) indicating the situation when teachers were against computers, but used them occasionally anyway for the sake to prove some ICT flavour in their teaching. The next chapter introduces the results of the meta-analysis.

\section{Results}

The five types of teacher agency manifestation, which derived from the meta-analysis, are the following: enthusiastic appropriation; pragmatic assimilation; reserved balancing act; hampered accommodation; and sceptical ritualism. Each type is described in detail below.

\section{Enthusiastic appropriation}

The meta-analysis indicated that there was a distinct group of teachers who had acknowledged the value of ICT in implementing student centred and inquiry based teaching and learning approaches. They saw the value of ICT in making their own lives at school more enjoyable and interesting by providing opportunities to experiment, develop and change their practice, and learn new things. Such attitudes to ICT were related to mastery achievement goal orientation. Teachers in this group held high ICT-related self-efficacy beliefs. These teachers supported students' use of technology in various ways, and actively helped them to develop skills for using, e.g., the Internet not only for information search, but for creative self-expression, thus serving as "windows" and active guides and coaches helping students to navigate through the "digital jungle". These teachers were the ones who were most enthusiastic towards involvement in teacher professional development and attending training related to ICT. Teachers in this group felt ownership towards the educational technology. One remarkable example in this group was a teacher of biology (Karaseva, 2016a) who integrated technology in her practice by putting much self-reflexivity in managing the challenges that came along with, e.g., in mediating students' use of ICT, helping them to acquire advanced skills in using various hardware and software, in planning and organizing teacher's own use of digital tools. However, it has to be noted that none of the teachers in this group were teaching subjects in which students according to Latvian and Estonian rules are to take centralized exams.

\section{Pragmatic assimilation}

Teachers in this group saw the value of ICT as far as it helped them to reduce some workload related to preparation for lessons, teaching, assessing 
student work. Such attitudes indicated orientation towards work avoidance goal (Karaseva et al, forthcoming). These teachers were convinced that their ICT skills are above average and, accordingly, they reported to be very active and confident ICT users; however, technology was adapted by them in ways which did not make big changes in teachers' already established, mainly teachercentred practices. This was related to several factors, mostly to strong beliefs about the nature of learning and the nature of technology, namely, the degree to which the ICT tools can support learning (Karaseva et al., 2015). Namely, some teachers held values and expressed opinions, which were contradictory to the approaches they relied on in their actual teaching practice. These teachers "in theory" acknowledged the creative potential and usefulness of various ICT tools for student-centred teaching, but their choices of using digital technology in ways, which supported teacher-centred learning. Such paradox was related to their perceived need to keep up with the curricula requirements and avoid possible risks of not preparing students sufficiently to the final exams. This was coupled with strong beliefs about students as rather inactive participants in the learning process: one of the teachers said during the interview that students actually want teaching-from-the-front. These teachers also practiced mostly gate-keeping mediation style and applied various techniques for structuring the students' use of computers during the lessons, e.g., by preparing detailed worksheets, giving closed-end tasks, preparing lists of "appropriate" web-sites to be used by students. Such practices were based on teachers' belief that students lacked skills and therefore needed guidance to use digital resources for serious learning purposes. These teachers also emphasized that they value high their established expert-of-ICT-use image, which was maintained through a set of activities: consulting colleagues on ICT-related matters, demonstrating special ICT skills (e.g., skills of filming and editing videos).

\section{Reserved balancing act}

Teachers in this group were rather cautious against the use of ICT. They did not fully neglect its educational value; rather their opinion was that technology can be integrated in teachers' work in some or another way, but always with utmost care and caution, keeping in mind in the words of one study participant that "less is better than too much". They had developed their attitude mainly due to their very strong relational goal orientation, which led them to beliefs that technology might seriously threaten their goals to establish and maintain warm and close relationships with their students, which, as they believed, was best developed with the help of face-to-face conversations and class interaction. At the same time, some relationalists had developed practices, which, they believed, helped deepening their relationships with students and lowering the hierarchy between students and themselves. E.g., they used to ask students help with finding some lesson materials online, help with 
troubleshooting etc., thus trying to demonstrate that teachers are "not always the cleverest ones in the class", as one of the teachers in Latvian sample said. Most teachers in this group rather firmly stated that they do not want to improve their ICT skills arguing they are not planning to intensify or modify their technology use. In addition, these teachers perceived their ICT usage skills and technological self-efficacy as moderate or pretty low (Karaseva, 2016b).

\section{Hampered accommodation}

Teachers in this group were convinced that they are possessing poor ICT skills, but at the same time they had positive general attitude towards technology use in teaching. They had developed different strategies, which were aimed to keep balance between maintaining teachers' authority in the eyes of students, and at the same time integrating some technology "flavour" in their teaching. For example, one teacher told that she used to select digital tools and resources very carefully, trying to predict also the level of technological competence of the students she had to work with, and then adjusting her ICT use accordingly in order not to expose incompetence. Teachers in this group showed concerns about potentially harmful content that the students might see online, therefore they always checked all the resources beforehand and kept and updated lists of "appropriate" resources, thus mainly acting as gate-keepers for students' use of digital technology (Karaseva et al., 2015). These teachers were keen on improving their ICT-related skills to keep up with the technological development.

\section{Sceptic ritualism}

This was a small group of teachers, mainly language teachers, who had developed a rather denying attitude towards ICT despite their overall good online skills (Karaseva, 2016b). The main claim among them was that they did not see the educational value of technology apart from being a tool, which can be used for relaxation, time passing, but not for serious learning. In the interview transcripts, it was labelled as well-justified resistance towards technology use based on teachers' biases towards ICT (Karaseva et al., 2015). During the interviews teachers referred mainly to the specifics of their subject cultures as the main reasons for the very limited use of digital tools. Their main claim was that they do not see how the digital technology could "fit" in their subject teaching, which as several of them believed, required active student involvement, live conversation in the classroom. However, teachers in this group could tell about few occasionally applied practices, which, in their opinion, gave some technological flavour to their teaching and therefore did not make them look as if they rejected ICT tools completely. They were, for example, asking students to make presentations about some subject-related topics, or allowing the best performing students to do exercises in the computer lab while other students stayed in the classroom and did tasks with pen and 
paper. Characteristic for teachers in this group was usage of ICT tools as substitutions of printed materials, e.g., textbooks, or turning on the smart board during the lessons, but only for demonstration, or using ICT as a relaxation tool, which students cold play with after the "serious work", in teachers` opinion, had been done.

\section{Discussion and conclusions}

It is acknowledged that teachers are rarely involved in designing educational changes; however, their reaction to the changes and involvement are crucial determinants of the success of the change (Ketellar et al., 2012). This study revealed that teachers understand ICT and integrate the use of digital technology in their work in different ways, which definitely do not fit in the often applied rejection - to - accommodation continuum (Stilman \& Anderson, 2015). As the findings indicate, teachers' professional agency is resourced both socially and individually, and has also elements of "situational character" (Layder, 1997: 92). Personal factors such as perceived self-efficacy and various teacher beliefs belonging to the psychobiographical domain (Layder, 1997) work as mediators in the process of reasoning about the situated activity, and the social and structural context. And vice versa: the situational features such as the interaction between teacher and student, and teacher and technology (the domain of situated activity) in combination with contextual pressures have their role in shaping the features on the psychobiographical domain.

It has been argued previously, the more teachers feel pressured from "above", being held responsible for students' performance, the more controlling, critical, directive and less creative they become, compared to their colleagues who do not experience such pressures (e.g., see Flink et al., 1990; Pelletier et al., 2002). As this study indicated, the need to prepare students for high-stakes exams triggered practices of ICT use, which support acquisition of particular skills or knowledge from curriculum, which teachers knew, will be tested in the exam. Teachers, who did not face the exam burden, felt much more free and creative in applying technology in their work, compared to their colleagues who are to prepare students for the centralized exams. The need to be in line with the societal and cultural demands motivated some teachers to develop practices of ICT use which led to reception of external rewards, e.g. in the form of appreciation and approval by the teacher community and other stakeholders such as parents, students. In several cases, it was still evident that teachers struggle to find meaningful ways to integrate ICT in their work. Sometimes it was related to overall low perceived technological competence, in other cases - strong subjectrelated identity. Therefore, it can be said that subject cultures seemed to be an important influencer of ICT integration in teaching, especially for justifying why 
technology does NOT fit in teaching the particular subject. Some teachers used references to subject cultures and particularly the subject boundaries as "bullet proof" arguments against the pressures to intensify the integration of ICT in their work.

To conclude, this study demonstrated that the interplay between different personal, situational, social and contextual aspects and their combinations shape and re-shape teachers' ICT practices. Variations in teacher agency manifestations reveal the conflict between different values, pressures, and demands, which teachers try to balance in order to fulfil their professional roles and responsibilities.

The current meta-study illustrated that factors, which create variances in teachers' responses to ICT policies, are not always necessarily directly linked to technology. This should be taken into account in designing the teacher training programs in future. For teacher trainers the results of this meta-study can serve as additional source of information to develop a better understanding of the variety of personal, situational, social and contextual factors, which influence teachers' practices of ICT use. Based on the findings it can be suggested that professional development inside schools, subject based peer-to-peer learning and shadowing of colleagues' work could help teachers to overcome fears about their technological self-efficacy or beliefs about limited affordances of technologies in education.

\section{References}

Apple, M. W. (1994). Computers and the deskilling of teaching. CPSR News, 12 (2), retrieved from: http://cpsr.org/prevsite/publications/newsletters/issues/1994/Spring1994/apple. html/

Bicevskis, J., Andzans, A., Ikaunieks, E., Medvedis, I., Straujums, U., \& Vezis, V. (2004). Latvian Education Information System LIIS. Education Media International, 41 (1), 43-50.

Coburn, C. (2004). Beyond Decoupling: Rethinking the relationship between the institutional environment and the classroom. Sociology of Education, 77 (3), 211-244.

Errs, M. (2015). The politics of teacher autonomy in Estonia, Germany, and Finland. PhD thesis. Tallinn University: Tallinn.

Eteläpelto, A., Vähäsantanen, K., Hökkä, P., \& Paloniemi, S. (2013). What is agency? Conceptualizing professional agency at work. Educational Research Review, 10, 45-65.

European Commission. (2014). The international computer and information literacy study (ICILS): Main findings and implications for education policies in Europe. Retrieved from: http://ec.europa.eu/education/library/study/2014/ec-icils_en.pdf.

Flink, C., Boggiano, K. M., \& Barrett, M. (1990). Controlling teaching strategies: Undermining children's self-determination and performance. Journal of Personality and Social Psychology, 59, 916-924.

Fuchs, S. (2001). Beyond agency. Sociological Theory, 19 (1), 24-40. 
Fullan, M. (2007). The New Meaning of Educational Change. New York and London: Teachers College Press.

Giddens, A. (1984). The Constitution of Society: Outline of the Theory of Structuration. Cambridge: Polity Press.

Hargreaves, A. (1994). Changing Teachers, Changing Times. Teachers' Work and Culture in the Postmodern Age. London: Cassell.

Hargreaves, Andy (2000). Four ages of professionalism and professional learning. Teachers and Teaching: Theory and Practice 6, 151-182.

Haydn, T. (2010). Lessons learned? Teaching student teachers to use ICT in their subject teaching: A view from the UK. Australian Educational Computing, 24 (2), 35-40.

Heijden, H. R. M. A van der, Geldens, J. J. M., Beijaard, D., \& Popeijus, H. L. (2015). Characteristics of teachers as change agents. Teachers and Teaching: Theory and Practice, 21 (6), 681-699.

Karaseva, A., Pruulmann-Vengerfeldt, P., \& Siibak, A. (2013). Comparison of Different Subject Cultures and Pedagogical Use of ICTs in Estonian Schools. Nordic Journal of Digital Literacy (3), pp. 157-171.

Karaseva, A., Siibak, A., \& Pruulmann-Vengerfeldt, P. (2015). Relationships between teachers' pedagogical beliefs, subject cultures, and mediation practices of students' use of digital technology. Cyberpsychology: Journal of Psychological Research on Cyberspace, 9 (1), no page number.

Karaseva, A., Siibak, A., \& Pruulmann-Vengerfeldt, P. (submitted). Relationships between in-service teacher achievement motivation and use of educational technology: case study with Latvian and Estonian teachers. Technology Pedagogy and Education, xx(x), pp-pp.

Karaseva, A. (2016a). Pedagogy of connection: teachers' experiences of promoting students' digital literacy. In O. Erstad, K.Kumpulainen, A. Mäkitalo, K. Schrøder, P. PruulmannVengerfeld, \& T. Jóhansdóttir (Eds.) Learning across contexts in the knowledge society. Rotterdam, The Netherlands: Sense Publishers.

Karaseva, A. (2016b). Relationship of Internet self-efficacy and online search performance of secondary school teachers. Procedia - Social and Behavioral Sciences (231), 278-285.

Kangro, A., \& Kangro, I. (2004). Integration of ICT in teacher education and different school subjects in Latvia. Educational Media International, 41 (1), 31-37.

Ketelaar, E., Beijaard, D., Boshuizen, H. P. A., \& Den Brok, P. J. (2012). Teachers' positioning towards an educational innovation in the light of ownership, sense-making and agency. Teaching and Teacher Education, 28, 273-282.

Kelchtermans, G. (2005). Teachers' emotions in educational reforms: Selfunderstanding,vulnerable commitment and micro political literacy. Teaching and teacher education, 21, 995-1006.

Kesküla, E., Loogma, K., Kolka, P., \& Sau-Ek, K. (2012). Curriculum change in teachers' experience: the social innovation perspective. Pedagogy, Culture and Society, 20, 353-376.

Kimber, K., Pillay, H., \& Richards, C. (2002). Reclaiming teacher agency in a student-centred digital world. Asia-Pacific Journal of Teacher Education, 30 (2), 155-167.

Lasky, S. (2005). A sociocultural approach to understanding teacher identity, agency and professional vulnerability in a context of secondary school reform. Teaching and Teacher Education, 21 (8), 899-916.

Layder, D (1993). New Strategies in Social Research: An Introduction and Guide. Cambridge: Polity Press. 
Layder, D. (1997). Modern Social Theory: Key Debates and New Directions. UCL Press: London and Bristol.

Leander, K. M, \& Osborne, M. D. (2008). Complex positioning: teachers as agents of curricula and pedagogical reform. Journal of Curriculum Studies, 40 (1), 23-46.

Lipponen, L., \& Kumpulainen, K. (2011). Acting as accountable authors: Creating interactional spaces for agency work in teacher education. Teaching and Teacher Education, 27, 812-819.

Loogma, K., Kesküla, E., \& Roosipõld, A. (2010). The Transformation of the Teaching Profession in Estonia: Changes in Professionalism. In J. Mikk, M. Veissson and P. Luik (eds), Teacher's Personality and Professionalism. Frankfurt AM: Peter Lang Verlag, 11-30.

Luttenberg, J., van Veen, K., \& Imants, J. (2013). Looking for cohesion: the role of search for meaning in the interaction between teacher and reform. Research Papers in Education, 28 (3), 289-308.

Merton, R. K. (1957). Social theory and social structure. Glencoe, IL: The Free Press.

Mägi, E. (2006). Issues in Estonia: The challenge of having fewer children! Thematic dossiers for observatory for the new technologies and education. Downloaded from: http://insight.eun.org/ww/en/pub/insight/thematic-dossiers/articles

OECD (2009). Creating effective teaching and learning environments: First results from TALIS 2008.Teaching and learning international survey. Paris: OECD.

Pelletier, G. L, Séguin-Lévesque, C., \& Legault, L. (2002). Pressure from above and pressure from below as determinants of teachers' motivation and teaching behaviour. Journal of Educational Psychology, 94 (1), 186-196.

Runnel, P., Pruulman-Vengerfeld, P., \& Reinsalu, K. (2009). Estonian Tiger Leap from postcommunism to the information society. Journal of Baltic Studies, 40 (1), 29-51.

Sannino, A. (2010). Teachers' talk of experiencing: conflict, resistance and agency. Teaching and Teacher Education, 26 (4), 838-844.

Schreiber, R., Crooks, D., \& Stern., P. N. (1997). Qualitative meta-analysis. In J.M.Morse (Ed.) Completing a Qualitative Project: Details and Dialogue (p. 311-326). Thousand Oaks, CA: Sage.

Selwyn, N. (2011). Schools and schooling in the Digital Age. A critical analysis. London and New York: Routledge.

Stillman, J., \& Anderson, L. (2015). From accommodation to appropriation: teaching, identity and authorship in a tightly coupled policy context. Teachers and Teaching: Theory and Practice, 21 (6), 720-744.

Tondeur, J., van Braak, J., \& Valcke, M. (2007). Curricula and the use of ICT in education: Two worlds apart? British Journal of Educational Technology, 38 (6), 962-976.

United Nations (2003). World Youth report: The global situation of young people. Chapter 12, retrieved from: http://www.un.org/esa/socdev/unyin/documents/ch12.pdf

Ward, S. C. (2012). Neoliberalism and the global restructuring of knowledge and education. New York and London: Routledge.

Vähäsantanen, K. (2015). Professional agency in the stream of change: Understanding educational change and teachers' professional identities. Teaching and Teacher Education, 47, 1-12.

Vähäsantanen, K., \& Billett, S. (2008). Negotiating professional identity: Vocational teachers' personal strategies in a reform context. In S. Billett, C. Harteis, \& A. Eteläpelto (Eds.), Emerging perspectives of workplace learning (pp. 35-49). Rotterdam: Sense Publishers. 
SOCIETY. INTEGRATION. EDUCATION

Proceedings of the International Scientific Conference. Volume III, May $26^{\text {th }}-27^{\text {th }}$, 2017. 500-514

Vähäsantanen, K., Hökkä, P., Eteläpelto, A., Rasku-Puttonen, H., \& Littleton, K. (2008). Teachers' professional identity negotiations in two different work organisations. Vocations and Learning, 1 (2), 131-148. 